\title{
Hubungan Pengetahuan, Budaya, Dan Pekerjaan Dengan Pemberian Makanan Bayi Usia 6-11 Bulan Di Lombok Tengah
}

\author{
Omiati Natalia \\ Email: omynatalia27@gmail.com
}

Program Studi Kebidanan/ Universitas Qamarul Huda Badaruddin Bagu

\begin{abstract}
ABSTRAK
Kebutuhan gizi bayi usia lebih dari 6 bulan baik makronutrien maupun mikronutrien tidak dapat terpenuhi hanya oleh ASI, oleh karena itu memulai pemberian MP ASI pada saat yang tepat akan sangat bermanfaat bagi pemenuhan kebutuhan gizi dan tumbuh kembang bayi. Penelitian ini bertujuan untuk mengetahui hubungan pengetahuan, budaya dan pekerjaan dengan pemberian makanan bayi 6-11 bulan di Lombok Tengah. Jenis penilitian ini adalah observasional analitik dengan rancangan studi potong lintang dengan jumlah sampel 156. Sampel dipilih dengan teknik Proportionate Stratified Random Sampling, kemudian sampel dari setiap srtata dipilih secara Systematic Random Sampling. Pengumpulan data dilakukan dengan wawancara terpimpin menggunakan kuesioner dan formulir food recall. Analisis multivariate dengan Regresi Logistik menggunakan metode Stepwise. Hasil penelitian menunjukkan bahwa pengetahuan berhubungan signifikan dengan pemberian makanan bayi dengan nilai $\mathrm{p}=0,000$, budaya berhubungan signifikan dengan pemberian makanan bayi dengan nilai $p=0,002$ dan pekerjaan berhubungan signifikan dengan pemberian makanan bayi dengan nilai $\mathrm{p}=0,005$. Disimpulkan bahwa pengetahuan, budaya dan pekerjaan berhubungan dengan pemberian makanan bayi 6-11 bulan di Lombok Tengah.
\end{abstract}

Kata kunci : pengetahuan, budaya, pekerjaan, pemberian makanan

\begin{abstract}
Nutritional needs of infants more than 6 months which both macronutrients and micronutrients can not completed only by breastmilk, therefore starting complementary food at the right time will be very beneficial for the needed of nutritional and infant growth needs. The aim of the research is to establish connecting which infant feeding 6-11 months (knowledge, culture and occupation) in Central Lombok Regency. The research was analytic observasional with cross sectional study design which consisted of 156 respondents.. The samples selected using Proportionate Stratified Random Sampling, then samples from every strata selected using Systematic Random Sampling. The samples consisted of 156 respondents. The data was collected by interviewing using questionnaires and food recall form. Multivariate analysis with stepwise method was used to look at the variables most corrected with infant feeding 6-11 months. They were multivariate analysis with Logistic Regression used Stepwise method. The results of the research indicate that knowledge significant correlated $(\mathrm{p}=0,000)$, culture significant correlated to infant feeding $(\mathrm{p}=0,002)$ and occupation significant correlated to infant feeding $(\mathrm{p}=0,005)$. The result of multivariate analysis with logistic regression indicates that knowledge, culture and occupation were correlated to infant feeding 6-11 months in Central Lombok Regency.
\end{abstract}

Key words : knowledge, culture, occupation, infant feeding

\section{A. LATAR BELAKANG}

Rekomendasi World Health Organization (WHO) dan United National Children's Fund (UNICEF) dalam Global Strategy for Infant and
Young Child Feeding[1], mengenai empat hal penting yang harus dilakukan guna mengoptimalkan tumbuh kembang anak yaitu; pertama memberikan air susu ibu kepada bayi 
segera dalam waktu 30 menit setelah bayi lahir, kedua memberikan hanya air susu ibu (ASI) saja atau pemberian ASI secara eksklusif sejak lahir sampai bayi berusia 6 bulan, ketiga memberikan makanan pendamping air susu ibu (MP-ASI) sejak bayi berusia 6 bulan sampai 24 bulan, dan keempat meneruskan pemberian ASI sampai anak berusia 24 bulan atau lebih.

Ikatan Dokter Anak Indonesia[2], menyatakan bahwa praktek pemberian MPASI dini sebelum usia enam bulan masih banyak dilakukan di negara berkembang seperti Indonesia. Hal ini akan berdampak terhadap kejadian infeksi yang tinggi, seperti diare, infeksi saluran napas, alergi, hingga gangguan pertumbuhan. Asupan gizi yang tidak tepat juga akan menyebabkan anak mengalami malnutrisi yang akhirnya meningkatkan angka morbiditas dan mortalitas. Menurut World Health Organization [3], pemberian makanan yang salah dalam masa 1000 hari pertama kelahiran umumnya irreversibel (sulit untuk dirubah kembali) dan akan berdampak pada kualitas hidup jangka pendek dan jangka panjang.

Motee et al [4], menyatakan bahwa prediktor menyusui dan praktek menyapih pada daerah perdesaan dan perkotaan berbeda. Beberapa faktor yang berpengaruh adalah usia, dukungan keluarga, pengetahuan tentang praktek pemberian makanan yang baik serta keyakinan di masyarakat. Beberapa hal yang berpengaruh menurut Andrews [5], menyebutkan bahwa dukungan keluarga dan status pekerjaan merupakan faktor yang berpengaruh terhadap pemilihan pemberian makanan bayi. Hasil penelitian Ogunba \& Olubukola [6], bahwa status pekerjaan ibu berkorelasi dengan pemberian makan pada bayi baik dari waktu, jenis maupun frekuensi. ibu bekerja cenderung memberikan susu formula dan makanan pendamping ASI dini yang dilakukan oleh pengasuhnya. Ibu bekerja cenderung memberikan susu formula dan bubur bayi sebagai pengganti ASI selama mereka bekerja[7].
Menurut Riskesdas [8], proses mulai menyusui terbanyak terjadi pada 1-6 jam setelah kelahiran $(35,2 \%)$ dan kurang dari 1 jam (inisiasi menyusui dini) sebesar $34,5 \%$. Sedangkan proses mulai menyusui terendah terjadi pada 7-23 jam setelah kelahiran yaitu sebesar 3,7\%. Mengacu pada target renstra pada tahun 2015 yang sebesar 39\%, maka secara nasional cakupan pemberian ASI eksklusif pada bayi usia kurang dari enam bulan sebesar 55,7\% telah mencapai target. Menurut provinsi, kisaran cakupan ASI eksklusif pada bayi umur 0-6 bulan antara 26,3\% (Sulawesi Utara) sampai $86,9 \%$ (Nusa Tenggara Barat). Menurut Profil Kesehatan Indonesia [9], dari 33 provinsi yang melapor, sebanyak 29 di antaranya (88\%) berhasil mencapai target renstra 2015 .

Pemberian makanan pada suku Sasak khususnya di Nusa Tenggara Barat masih ditemukan pemberian makanan prelakteal dan makanan pendamping ASI dini [10]. Penelitian ini ingin menilai besarnya hubungan pengetahuan, budaya dan pekerjaan ibu dengan pemberian makanan bayi 6-11 bulan pada suku Sasak. Tujuan penelitian adalah untuk mengetahui determinan pemberian makanan bayi 6-11 bulan pada suku Sasak di wilayah kerja Puskesmas Ganti Kabupaten Lombok Tengah.

\section{B. METODE PENELITIAN}

1. Lokasi Dan Rancangan Penelitian

Penelitian ini dilakukan di wilayah kerja Puskesmas Ganti, Kabupaten Lombok Tengah. Jenis penilitian ini adalah observasional analitik dengan rancangan studi potong lintang.

2. Populasi dan Sampel

Populasi adalah seluruh ibu yang memiliki bayi usia 6-11 bulan di wilayah kerja Puskesmas Ganti Kabupaten Lombok Tengah. Teknik sampling dengan teknik Proportionate Stratified Random Sampling, kemudian sampel dari setiap srtata dipilih secara Systematic Random Sampling. Total sampel sebanyak 156 responden. 
3. Metode Pengumpulan Data

Pengumpulan data dilakukan oleh peneliti sendiri dan menggunakan kuesioner. Data umum yang dikumpulkan (usia, pendidikan), sosial dan ekonomi (dukungan keluarga, pengetahuan, pekerjaan sikap), budaya (kepercayaan tentang ASI dan MP ASI), diukur dengan wawancara menggunakan daftar pertanyaan (kuesioner). Data ketepatan pemberian makanan bayi diukur dengan menggunakan daftar pertanyaan (kuesioner) dan formulir food recall 24 jam (selama 3 hari yang dipilih acak) untuk mengetahui jenis, konsistensi, porsi dan frekuensi pemberian makanan bayi 6-11 bulan.

4. Analisis Data

Pengolahan data menggunakan bantuan SPSS. Mengetahui hubungan usia, pendidikan, pengetahuan, sikap, pekerjaan, dukungan keluarga dan budaya menggunakan uji Chi Square. Sedangkan untuk mengetahui variabel yang paling berhubungan dengan pemberian makanan bayi digunakan uji multivariat Regresi Logistik dengan metode Stepwise.

\section{HASIL DAN PEMBAHASAN}

1. Karakteristik Sampel

Tabel 1. Distribusi Frekuensi Variabel Independent

\begin{tabular}{|c|c|c|c|}
\hline Variabel & Kategori & $\mathrm{n}$ & $\%$ \\
\hline \multirow{2}{*}{ Usia } & Resiko tinggi & 31 & 19,9 \\
\hline & Resiko rendah & 125 & 80,1 \\
\hline \multirow[t]{3}{*}{ Pendidikan } & Rendah & 16 & 10,3 \\
\hline & Menengah & 132 & 84,6 \\
\hline & Tinggi & 8 & 5,1 \\
\hline \multirow[t]{2}{*}{ Pengetahuan } & Cukup & 108 & 69,2 \\
\hline & Kurang & 48 & 30,8 \\
\hline \multirow[t]{2}{*}{ Sikap } & Cukup & 63 & 40,4 \\
\hline & Kurang & 93 & 59,6 \\
\hline \multirow[t]{2}{*}{ Pekerjaan } & Bekerja & 46 & 29,5 \\
\hline & Tidak bekerja & 110 & 70,5 \\
\hline \multirow{2}{*}{$\begin{array}{l}\text { Dukungan } \\
\text { keluarga }\end{array}$} & Mendukung & 72 & 46,2 \\
\hline & Tidak mendukung & 84 & 53,8 \\
\hline \multirow[t]{2}{*}{ Budaya } & Mendukung & 105 & 67,3 \\
\hline & Tidak mendukung & 51 & 32,7 \\
\hline \multicolumn{2}{|l|}{ Total } & 156 & 100 \\
\hline
\end{tabular}

Sebagian besar responden berusia 20-35 tahun $(80,1 \%)$ yang merupakan kelompok usia reproduksi sehat. Berdasarkan aspek sosial ekonomi yang dinilai yaitu tingkat pendidikan dan pekerjaan ibu menunjukkan bahwa sebagian reponden dalam kategori pendidikan menengah $(84,6 \%)$, dengan $(70,5 \%)$ ibu tidak bekerja. Prevalensi ibu yang memiliki sikap kurang positif $(70,5 \%)$. Ibu yang tidak mendapat dukungan keluarga $(53,8 \%)$ dan prevalensi budaya yang mendukung $(67,3 \%)$.

\section{Analisis Bivariat}

Tabel 2 menunjukkan proporsi ketepatan pemberian makanan bayi 6-11 bulan pada suku Sasak. Proporsi pemberian makanan dalam kategori tidak tepat pada kelompok resiko tinggi $(80,6 \%)$ lebih tinggi dibandingkan responden dalam kategori resiko rendah $(18,4 \%)$ dengan nilai $\mathrm{p}=0,000$. Responden dalam kategori pendidikan rendah sebesar $100 \%$ tidak tepat dalam pemberian makanan bayi, sedangkan pendidikan menengah $23,5 \%$ dan pendidikan tinggi $12,5 \%$ dengan nilai $\mathrm{p}=0,000$. Proporsi pemberian makanan dalam kategori tidak tepat lebih rendah pada responden dengan pengetahuan cukup (12\%) dibandingkan responden dengan pengetahuan kurang ( $72,9 \%)$ dengan nilai $\mathrm{p}=0,000$. Responden dengan sikap positif sebesar $4,8 \%$ tidak tepat dalam pemberian makanan bayi, sedangkan responden dengan sikap negatif sebesar $48,4 \%$ tidak tepat dalam pemberian makanan bayi dengan nilai $p=0,000$. Responden yang bekerja $(71,7 \%)$ tidak tepat dalam pemberian makanan bayi dan responden yang tidak bekerja $(13,6 \%)$ tidak tepat dalam pemberian makanan bayi dengan nilai $p=0,000$. Proporsi pemberian makanan dalam kategori tidak tepat lebih rendah pada responden yang mendapat dukungan keluarga (5,6\%) dibandingkan responden yang tidak mendapat dukungan keluarga $(52,4 \%)$ dengan nilai $p=0,000$. 
Tabel 2. Distribusi frekuensi variable usia, pendidikan, pengetahuan, sikap, pekerjaan, dukungan keluarga dan budaya dan hubungan setiap variabel independen dengan pemberian makanan bayi 6-11

\begin{tabular}{|c|c|c|c|c|c|c|c|c|}
\hline \multirow{3}{*}{ Variabel } & \multirow{3}{*}{ Kategori } & \multicolumn{4}{|c|}{$\begin{array}{c}\text { Ketepatan Pemberian } \\
\text { Makanan }\end{array}$} & \multirow{3}{*}{$\mathrm{n}$} & \multirow{3}{*}{$\%$} & \multirow{3}{*}{ Nilai $p$} \\
\hline & & \multicolumn{2}{|c|}{ Tepat } & \multicolumn{2}{|c|}{ Tidak } & & & \\
\hline & & $\mathrm{n}$ & $\%$ & $\mathrm{n}$ & $\%$ & & & \\
\hline \multirow[t]{2}{*}{ Usia } & Resiko tinggi & 6 & 19,4 & 25 & 80,6 & 31 & 19,9 & \multirow[t]{2}{*}{0,000} \\
\hline & Resiko rendah & 102 & 81,6 & 23 & 18,4 & 125 & 80,1 & \\
\hline \multirow[t]{3}{*}{ Pendidikan } & Rendah & 0 & 0,0 & 16 & 100 & 16 & 10,3 & \multirow[t]{3}{*}{0,000} \\
\hline & Menengah & 101 & 76,5 & 31 & 23,5 & 132 & 84,6 & \\
\hline & Tinggi & 7 & 87,5 & 1 & 12,5 & 8 & 5,1 & \\
\hline \multirow[t]{2}{*}{ Pengetahuan } & Cukup & 95 & 88,0 & 13 & 12,0 & 108 & 69,2 & \multirow[t]{2}{*}{0,000} \\
\hline & Kurang & 13 & 27,1 & 35 & 72,9 & 48 & 30,8 & \\
\hline \multirow[t]{2}{*}{ Sikap } & Cukup & 60 & 95,2 & 3 & 4,8 & 63 & 40,4 & \multirow[t]{2}{*}{0,000} \\
\hline & Kurang & 48 & 51,6 & 45 & 48,4 & 93 & 59,6 & \\
\hline \multirow[t]{2}{*}{ Pekerjaan } & Bekerja & 13 & 28,3 & 33 & 71,7 & 46 & 29,5 & \multirow[t]{2}{*}{0,000} \\
\hline & Tidak bekerja & 95 & 86,4 & 15 & 13,6 & 110 & 70,5 & \\
\hline \multirow{2}{*}{$\begin{array}{l}\text { Dukungan } \\
\text { keluarga }\end{array}$} & Mendukung & 68 & 94,4 & 4 & 5,6 & 72 & 46,2 & \multirow[t]{2}{*}{0,000} \\
\hline & Tidak mendukung & 40 & 47,6 & 44 & 52,4 & 84 & 53,8 & \\
\hline \multirow[t]{2}{*}{ Budaya } & Mendukung & 96 & 91,4 & 9 & 8,6 & 105 & 67,3 & \multirow[t]{2}{*}{0,000} \\
\hline & Tidak mendukung & 12 & 23,5 & 39 & 76,5 & 51 & 32,7 & \\
\hline \multicolumn{2}{|l|}{ Total } & 108 & 69,2 & 48 & 30,8 & 156 & 100 & \\
\hline
\end{tabular}

Proporsi pemberian makanan dalam kategori tidak tepat lebih tinggi adanya budaya yang tidak mendukung (76,5\%) dibandingkan dengan budaya yang tidak mendukung $(8,6 \%)$ dengan nilai $p=0,000$. Dari 7 variabel independen yang dilakukan uji chi-square semua variabel berhubungan signifikan dengan pemberian makanan bayi 6-11 bulan.

\section{Analisis Multivariat}

Tabel 3 memperlihatkan bahwa variabel yang termasuk faktor yang berhubungan dengan pemberian makanan bayi 6-11 bulan pada suku Sasak. Hasil uji regresi logistik dengan metode Stepwise yang dinilai melalui tingkat signifikansi (Sig) dan memperlihatan bahwa dari 7 variabel independen yang dimasukkan ke dalam uji secara simultan ada 5 variabel yang memberi nilai signifikansi, yakni variabel pendidikan, pengetahuan, pekerjaan, dukungan keluarga dan budaya. Hal ini dapat dilihat dari hasil analisis multivariat yang diuraikan sebagai berikut: Pendidikan dengan nilai $(\mathrm{p}=0,026)$, pengetahuan, dengan nilai $(\mathrm{p}=0,000)$, dukungan keluarga, dengan nilai $(\mathrm{p}=0,042)$ dan budaya dengan nilai $(p=0,002)$.

Hasil analisis yang terlihat pada tabel 4 didapatkan persentase pengaruh variabel pengetahuan, budaya, pekerjaan, sikap, pendidikan dan dukungan keluarga terhadap pemberian makanan bayi 6-11 bulan pada suku Sasak yaitu sebesar $88,2 \%$.

Berdasarkan tabel 3 dan 4 didapatkan informasi bahwa variabel yang paling besar hubungannya dengan ketepatan pemberian makanan bayi 6-11 bulan pada suku Sasak adalah pengetahuan dengan nilai $60,3 \%$; budaya $12,8 \%$, pekerjaan $7,2 \%$, sikap $3,5 \%$, pendidikan 2,6\% dan dukungan keluarga $1,8 \%$. Dari analisis multivariat didapatkan bahwa variabel yang paling berhubungan dengan pemberian makanan adalah pengetahuan. 
Tabel 3. Hasil Analisis Multivariat Determinan Pemberian Makanan Bayi 6-11 Bulan Pada Suku

\begin{tabular}{|c|c|c|c|c|c|}
\hline \multicolumn{6}{|c|}{ Sasak } \\
\hline & & $\mathrm{B}$ & Df & Sig. & $\begin{array}{l}\text { Exp } \\
\text { (B) }\end{array}$ \\
\hline \multirow[t]{2}{*}{ Step1 } & $\begin{array}{l}\text { Pengeta } \\
\text { huan }\end{array}$ & 1,683 & 1 & 0,000 & 5,379 \\
\hline & $\begin{array}{l}\text { Consta } \\
\text { nt }\end{array}$ & $\begin{array}{l}- \\
16,33 \\
5\end{array}$ & 1 & 0,000 & 0,000 \\
\hline \multirow[t]{3}{*}{ Step2 } & $\begin{array}{l}\text { Pengeta } \\
\text { huan }\end{array}$ & 1,503 & 1 & 0,000 & 4,494 \\
\hline & Budaya & 0,994 & 1 & 0,000 & 2,702 \\
\hline & $\begin{array}{l}\text { Consta } \\
\text { nt }\end{array}$ & $\begin{array}{l}- \\
22,85 \\
3\end{array}$ & 1 & 0,000 & 0,000 \\
\hline \multirow[t]{4}{*}{ Step3 } & $\begin{array}{l}\text { Pengeta } \\
\text { huan }\end{array}$ & 1,433 & 1 & 0,000 & 4,190 \\
\hline & $\begin{array}{l}\text { Pekerja } \\
\text { an }\end{array}$ & 2,770 & 1 & 0,000 & $\begin{array}{l}15,95 \\
1\end{array}$ \\
\hline & Budaya & 1,094 & 1 & 0,000 & 2,985 \\
\hline & $\begin{array}{l}\text { Consta } \\
\text { nt }\end{array}$ & $\begin{array}{l}- \\
24,62 \\
8\end{array}$ & 1 & 0,000 & 0,000 \\
\hline \multirow[t]{5}{*}{ Step4 } & $\begin{array}{l}\text { Pengeta } \\
\text { huan }\end{array}$ & 1,436 & 1 & 0,000 & 4,202 \\
\hline & Sikap & 0,223 & 1 & 0,009 & 1,249 \\
\hline & $\begin{array}{l}\text { Pekerja } \\
\text { an }\end{array}$ & 2,711 & 1 & 0,001 & $\begin{array}{l}15,03 \\
7\end{array}$ \\
\hline & Budaya & 1,029 & 1 & 0,000 & 2,799 \\
\hline & $\begin{array}{l}\text { Consta } \\
\text { nt }\end{array}$ & $\begin{array}{l}- \\
35,58 \\
7\end{array}$ & 1 & 0,000 & 0,000 \\
\hline \multirow[t]{6}{*}{ Step5 } & $\begin{array}{l}\text { Pendidi } \\
\text { dikan }\end{array}$ & 4,333 & 1 & 0,072 & $\begin{array}{l}76,17 \\
8\end{array}$ \\
\hline & $\begin{array}{l}\text { Pengeta } \\
\text { huan }\end{array}$ & 1,507 & 1 & 0,000 & 4,515 \\
\hline & Sikap & 0,211 & 1 & 0,021 & 1,235 \\
\hline & $\begin{array}{l}\text { Pekerja } \\
\text { an }\end{array}$ & 2,778 & 1 & 0,001 & $\begin{array}{l}16,09 \\
3\end{array}$ \\
\hline & Budaya & 0,980 & 1 & 0,000 & 2,663 \\
\hline & $\begin{array}{l}\text { Consta } \\
\text { nt }\end{array}$ & $\begin{array}{l}- \\
43,86 \\
0\end{array}$ & 1 & 0,000 & 0,000 \\
\hline \multirow[t]{7}{*}{ Step6 } & $\begin{array}{l}\text { Pendidi } \\
\text { kan }\end{array}$ & 5,496 & 1 & 0,026 & $\begin{array}{l}243,6 \\
8\end{array}$ \\
\hline & $\begin{array}{l}\text { Pengeta } \\
\text { huan }\end{array}$ & 1,649 & 1 & 0,000 & 5,201 \\
\hline & Sikap & 0,175 & 1 & 0,056 & 1,191 \\
\hline & $\begin{array}{l}\text { Pekerja } \\
\text { an }\end{array}$ & 2,594 & 1 & 0,005 & $\begin{array}{l}13,37 \\
7\end{array}$ \\
\hline & $\begin{array}{l}\text { Dukun } \\
\text { gan }\end{array}$ & 0,073 & 1 & 0,042 & 1,076 \\
\hline & Budaya & 0,942 & 1 & 0,002 & 2,565 \\
\hline & $\begin{array}{l}\text { Consta } \\
\text { nt }\end{array}$ & $\begin{array}{l}- \\
50,90 \\
9\end{array}$ & 1 & 0,000 & 0,000 \\
\hline
\end{tabular}

Tabel 4. Model summary pemberian makanan bayi 6-11 bulan pada suku Sasak di wilayah kerja Puskesmas Ganti, Kabupaten Lombok Tengah

\begin{tabular}{|c|c|c|c|}
\hline Step & $\begin{array}{c}-2 \text { Log } \\
\text { likelihood }\end{array}$ & $\begin{array}{c}\text { Cox \& } \\
\text { Snell R } \\
\text { Square }\end{array}$ & $\begin{array}{c}\text { Nagelkerke R } \\
\text { Square }\end{array}$ \\
\hline 1 & $105,495^{\text {a }}$ &, 428 &, 603 \\
\hline 2 & $78,655^{\mathrm{b}}$ &, 518 &, 731 \\
\hline 3 & $61,114^{\mathrm{b}}$ &, 569 &, 803 \\
\hline 4 & $51,975^{\mathrm{c}}$ &, 594 &, 838 \\
\hline 5 & $44,633^{\mathrm{c}}$ &, 613 &, 864 \\
\hline 6 & $39,403^{\mathrm{d}}$ &, 625 &, 882 \\
\hline
\end{tabular}

4. Pembahasan

Penelitian menemukan bahwa ada beberapa faktor yang secara signifikan berhubungan dengan pemberian makanan bayi 6-11 bulan pada suku Sasak adalah pengetahuan, budaya dan pekerjaan.

Pengetahuan merupakan hal yang sangat penting untuk terbentuknya tindakan seseorang, tindakan yang didasari oleh pengetahuan akan lebih langgeng daripada perilaku yang tidak didasari oleh pengetahuan [11]. Hasil uji multivariat dengan metode Stepwise menunjukkan bahwa nilai $\mathrm{p}=0,000$. Kontribusi pengetahuan dalam ketepatan pemberian makanan bayi sebesar 60,3\%. Besarnya kontribusi pengetahuan paling besar dibandingkan dengan variabel yang lain. Demikian juga hasil penelitian oleh Vaarno[12], yang mengukur pengetahuan ibu dalam pemberian makanan bayi (ASI dan MP ASI) diperoleh nilai $p=0,008(\alpha<0,05)$ yang artinya ada hubungan antara pengetahuan ibu dengan pemberian makanan bayi. Demikian juga yang hasil penelitian oleh Eckhardt et al [13] pada suku Latina menyatakan bahwa pengetahuan ibu yang baik akan berpengaruh tindakan kemampuan ibu dalam mengasuh anak.

Pengetahuan tentang pemberian makanan yang baik akan berpengaruh terhadap persepsi ibu mengenai bayi yang sehat serta kebutuhan bayi sesuai usia, sehingga ibu yang memiliki pengetahuan baik akan memberikan makanan kepada bayi 
secara tepat baik dari segi porsi, frekuensi, konsistensi dan jenis. Pengetahuan tentang pemberian makanan bayi didapatkan dari berbagai sumber, misalnya pendidikan kesehatan oleh tenaga kesehatan dalam hal ini adalah petugas dari Puskesmas Ganti, kader posyandu yang sudah mendapatkan pelatihan dari Dinas Kesehatan, Buku Posyandu (tertera penjelasan disertai gambar mengenai pemberian makanan yang tepat) serta media cetak, elektronik maupun pengalaman dari lingkungan. Informasi yang dikombinasikan dengan pemahaman mengenai ketepatan pemberian makanan akan mendatangkan kemampuan prediktif pada ibu untuk mengkondisikan bayi mendapatkan makanan yang tepat baik dari segi jenis, porsi, konsistensi maupun frekuensi.

Peran budaya terhadap kesehatan masyarakat adalah membentuk, mengatur dan mempengaruhi tindakan atau kegiatan individu dalam suatu kelompok sosial untuk memenuhi berbagai kebutuhan kesehatan. Budaya juga mengambil peran dalam pemberian makanan bayi.

Hasil penelitian ditemukan adanya budaya yang mendukung dan tidak mendukung dalam pemberian makanan bayi. Hasil uji statistik Chi Square diperoleh nilai $\mathrm{p}=0,000$, dan uji multivariat dengan metode Stepwise menunjukkan bahwa nilai $\mathrm{p}=0,002$ $(\alpha<0,05)$. Kedua nilai tersebut menggambarkan bahwa budaya berhubungan signifikan dengan pemberian makanan bayi 6-11 bulan pada suku Sasak. Budaya berkontribusi sebesar 12,8\% dalam ketepatan pemberian makanan bayi. Besarnya kontribusi budaya diasumsikan karena budaya merupakan hal yang paling melekat pada masyarakat sebagai makhluk sosial seperti kebiasaan dan kepercayaan masyarakat mengenai pemberian makanan bayi.

Penelitian yang dilakukan pada etnis di pedalaman Vietnam oleh Nguyen et al [14], melaporan bahwa budaya lokal berpengaruh dalam praktek pemberian makanan. Sejalan dengan hasil penelitian yang dilakukan oleh Pak-Gorstein et al [15], melaporkan bahwa budaya mempengaruhi praktek pemenuhan gizi pada anak, baik budaya yang menguntungkan maupun budaya yang merugikan. Demikian juga hasil penelitian Solomon [16], yang melaporkan bahwa perbedaan budaya pada setiap daerah berpengaruh terhadap praktek pemberian makanan bayi.

Kebiasaan pemberian makanan bayi merupakan salah satu produk budaya yang secara tidak langsung mempengaruhi ibu dalam pengasuhan bayi. Budaya merupakan kebiasaan turun temurun dari nenek moyang yang dianggap sakral pada beberapa daerah. Kemajuan teknologi serta terjadinya perubahan paham terhadap beberapa nilai budaya seiring mempengaruhi kebiasaan masyarakat terutama untuk pemenuhan kebutuhan kesehatan.

Masyarakat suku Sasak adalah masyarakat yang masih menghargai saran dan kepercayaan dari para tetua, misalnya mertua atau bahkan dukun yang dianggap sebagai “orang pintar". Namun tidak sedikit dari kepercayaan atau kebiasaan lama yang berefek negatif untuk bayi. Kepercayaan seperti "susu basi" merupakan kepercayaan yang masih berkembang sampai sekarang, karena mereka beranggapan bahwa susu berwarna agak kekuningan (kolostrum) tersebut akan menimbulkan penyakit untuk bayi.

Hubungan lingkungan bermasyarakat di suku Sasak yang terjaga dengan baik menjadi sarana penyebaran informasi maupun pengalaman mengenai pengasuhan anak terutama dalam pemberian makanan bayi. Sifat kekeluargaan yang masih kental membuat seseorang tidak sungkan untuk bertanya atau sekedar berbagi cerita mengenai pengalaman positif maupun negatif dalam mengasuh anak. 
Pemberian makanan pada suku Sasak tentu memiliki ciri khas tersendiri dibandingkan dengan suku lain. Misalnya, budaya pemberian makanan nasi papak sebagai makanan prelakteal serta anggapan bahwa bayi rewel adalah tanda bayi lapar sehingga kerap kali ditemukan bayi yang diberikan makanan pendamping ASI sebelum usia 6 bulan.

Budaya seperti dua sisi mata uang, selain mendatangkan efek yang merugikan juga ada hal bermanfaat yang didatangkan dilihat dari segi kesehatan. Kepercayaan serta kebiasaan masyarakat suku Sasak dalam pemberian ASI hingga usia bayi 2 tahun atau usia sapih 2 tahun jelas sangat menguntungkan baik untuk bayi, ibu maupun keluarga. Kepercayaan lain yang menguntungkan adalah tindakan membersihkan payudara sebelum menyusui bayi dengan tujuan agar bayi tidak diganggu oleh makhluk halus.

Kemajuan teknologi serta informasi di masa digital ternyata juga sudah menyentuh masyarakat suku Sasak di lokasi penelitian. Mudahnya akses informasi baik dari petugas kesehatan maupun media massa berpengaruh terhadap perilaku kesehatan masyarakat setempat, terutama dalam pemberian makanan bayi. Budaya pemberian makanan prelakteal seperti nasi papak memang masih ditemukan namun sangat sedikit jumlahnya.

Pekerjaan ibu adalah kesibukan yang harus dilakukan terutama untuk menunjang kehidupannya dan kehidupan keluarga. Status pekerjaan ibu berpengaruh terhadap pemberian makanan bayi, terlebih pada ibu yang bekerja di sektor formal. Mereka yang sebagian waktunya digunakan diluar rumah sehingga waktu untuk mengurus anak terbatas, oleh karena itu ibu bekerja cenderung akan menemukan kendala dalam pemberian ASI maupun MP ASI.

Hasil analisis bivariat memperolah nilai $\mathrm{p}=0,000$ yang artinya pekerjaan berhubungan signifikan dengan pemberian makanan bayi. Hal tersebut juga sesuai dengan hasil penelitian yang dilakukan oleh Onah et al [17], diperoleh nilai $\mathrm{p}=0,01$ yang artinya terdapat hubungan antara pekerjaan ibu dengan pemberian makanan bayi. Demikian juga penelitian yang dilakukan oleh Udoudo \& Ajayi [18], pada 324 ibu pekerja $(84,5 \%)$ menyatakan mengalami kesulitan dalam pemberian makanan bayi.

Terbatasnya waktu yang dimiliki oleh ibu bekerja dalam mengasuh anak terutama saat pemberian makanan menjadikan ibu bekerja memilih hal-hal yang lebih praktis. Misalnya, ibu bekerja cenderung memberikan susu formula kepada bayi $<6$ bulan sebagai pendamping ASI atau bahkan sebagai pengganti ASI. Memberikan MP ASI sebelum waktunya dikarenakan alasan kurangnya asupan ASI yang diberikan selama ibu bekerja.

Analisis multivariat dengan metode Stepwise menunjukkan hubungan pekerjaan dengan pemberian makanan bayi dan menggambarkan kontribusi pekerjaan dalam ketepatan pemberian makanan bayi sebesar $7,2 \%$. Ibu yang bekerja sebagai PNS (50\%) tidak memberikan makanan dengan tepat pada bayinya. Hal ini dimungkinkan karena waktu dan kesibukan pekerjaan berkontribusi dalam ketidaktepatan ibu untuk memberikan makanan bayi.

\section{KESIMPULAN}

Hasil analisis data penelitian yang telah dilakukan pada akhirnya ditarik kesimpulan bahwa pengetahuan signifikan berhubungan dengan pemberian makanan bayi 6-11 bulan. Disamping itu, budaya dan pekerjaan ibu juga memiliki hubungan dengan pemberian makanan bayi 6-11 bulan. Upaya peningkatan pengetahuan pada reponden harus tetap diupayakan baik melalui pendidikan kesehatan maupun demonstrasi pembuatan makanan bayi yang tepat sesuai usia. Pemanfaatan posyandu dan kader posyandu untuk menyadarkan masyarakat bahwa ada beberapa budaya yang 
mendukung dan budaya yang tidak mendukung pemberian makanan bayi 6-11 bulan.

\section{DAFTAR PUSTAKA}

[1] World Health Organization (WHO) \& United Nations International Children's Emergency Fund UNICEF). (2003). Global Strategy On Infant And Young Child. Geneva: World Health Organization

[2] Ikatan Dokter Anak Indonesia (IDAI). (2015). Rekomendasi Praktik Pemberian Makan Berbasis Bukti pada Bayi dan Batita di Indonesia untuk Mencegah Malnutrisi. Jakarta: Ikatan Dokter Anak Indonesia.

[3] World Health Organization (WHO). (2015). Infant And Young Child Feeding. http://www.who.int/mediacentre/factsheet s/fs342/en/. Diakses tanggal 23 Maret 2017.

[4] Motee A., Ramasawmy D., Gunsam P.P., \& Jeewon R. (2013). An Assessment of the Breastfeeding Practices and Infant Feeding Pattern among Mothers in Mauritius. Journal of Nutrition and Metabolism, Volume 2013 (2013), Article ID 243852, 8 pages.

[5] Andrews S.J. (2014). Best for baby : what factors influence new mothers when choosing between breastfeeding and bottle feeding babies under the age of two. Smith Collage, Theses, Dissertations, and Projects. Paper 751.

[6] Ogunba \& Olubukola B. (2015). Effect of Maternal Employment on Infant Feeding Practices in Southwestern Nigeria. Food and Nutrition Sciences, 6, 597-604.

[7] Murage E.W., Wekesah F., Wanjohi M., Kyobutungi C. Ezeh A.C., Musoke R.N et al. (2015). Factors Affecting Actualisation Of The Who Breastfeeding Recommendations In Urban Poor Settings In Kenya. Maternal and Child Nutrition, 11, pp. 314-332.

[8] Riset Kesehatan Dasar (Riskesdas). (2013). Badan Penelitian dan Pengembangan Kesehatan Kementerian RI tahun 2013. Jakarta: Kesehatan Kementerian RI.

[9] Depertemen Kesehatan RI. (2015). Profil Kesehatan Indonesia. Jakarta: Departemen Kesehatan RI.
[10] Utami N.H., Fahmida U., \& Santika O. (2011). Praktik Pemberian Makan Bayi Yang Tidak Tepat Belum Banyak Mengalami Perubahan Dalam Satu Dekade Terakhir Di Lombok Timur. The Journal Of Nutrition And Food Research 34(1):75-85.

[11] Notoatmodjo S. (2010). Metedologi Penelitian Kesehatan. Jakarta: Rineka Cipta

[12] Vaarno J. (2016). Parental Influences And Mothers' Experiences On Infant And Young Child Feeding. Turun yliopisto. Universitas of Turku

[13] Eckhardt C.L., Lutz T., Karanja N., \& Jobe J.B. (2014). Knowledge, Attitudes and Beliefs That May Influence Infant Feeding Practices in American Indian Mothers. Journal Academy of Nutrition and Dietetics. 114(10): 1587-1593.

[14] Nguyen T.T., Nguyen P.H., Hajeebhoy N., Nguyen H.V., \& Frongillo E.A. (2016). Infant And Young Child Feeding Practices Differ By Ethnicity Of Vietnamese Mothers. BMC Pregnancy and Childbirth 16:214.

[15] Pak-Gorstein S., Haq A., \& Graham E.A. (2009). Cultural Influences On Infant Feeding Practice. U.S National Library of Medicine, Vol.30 No.3.

[16] Solomon B.S.K. (2010). Socio-Cultural Factors Influencing Infant Feeding Practices Of Mothers Attending Welfare Clinic In Cape Coast. http://www.ifranigeria.org/IMG/pdf/Sika.pdf. Diakses 6 Juni 2017.

[17] Onah S., Chidiebere D.I., Ebenebe J., Ezechukwu C., Ekwochi U., \& Ndukwu U. (2014). Infant Feeding Practices And Maternal Socio-Demographic Factors That Influence Practice of Exclusive Breastfeeding Among Mothers In Nnewi South-East Nigeria: A Cross-Sectional And Analytical Study. International Breastfeeding Journal 9:6.

[18] Udoudo \& Ajayi. (2015). Working Mother Attitude and Practices of Exclusive Breastfeeding in Amac, Fct-Abuja. International Journal of Research in Sociology and Anthropology (IJRSA) Volume 1, Issue 1, 2015, PP 28-36 